The submitted manuscript has been authored by a contractor of the U.S. Government under contract No. DE-AC05-00OR22725. Accordingly, the U.S. Government retains a nonexclusive, royaltyfree license to publish or reproduce the published form of this contribution, or allow others to do so, for U.S. Government purposes.

\title{
Fusion Ignition Research Experiment Vacuum Vessel Design and Configuration*
}

\author{
B. Nelson [1], T. Burgess [1], T. Brown [2], H-M Fan [2], P. Heitzenroeder [2]
}

[1] Oak Ridge National Laboratory, P.O. Box 2009, Oak Ridge, TN 37831-8073

[2] Princeton Plasma Physics Laboratory, P.O. Box 451, Princeton, NJ 08543

14th ANS Topical Meeting on the Technology of Fusion Energy

October 16-20, 2000

Park City, Utah

\footnotetext{
${ }^{*}$ Research sponsored by the Office of Fusion Energy Sciences, U.S. Department of Energy under contract DE-AC0500OR22725 with UT-Battelle, LLC.
} 



\title{
Fusion Ignition Research Experiment Vacuum Vessel Design and Configuration
}

\author{
B. Nelson [1], T. Burgess [1], T. Brown [2], H-M Fan [2], P. Heitzenroeder [2] \\ [1] Oak Ridge National Laboratory, P.O. Box 2008, Oak Ridge, TN 37831-8073 \\ [2] Princeton Plasma Physics Laboratory, P.O. Box 451, Princeton, NJ 08543
}

\begin{abstract}
The design status of the vacuum vessel for the Fusion Ignition Research Experiment (FIRE) is presented. The purpose and configuration of the various components of the vessel are described, along with the results of preliminary structural analysis. It appears that a vessel can be designed to meet the requirements within the rather restricted space constraints.
\end{abstract}

\section{INTRODUCTION}

The Fusion Ignition Research Experiment (FIRE) is proposed as a versatile, high field tokamak that will investigate near-ignition $(\mathrm{Q}>10)$ deuterium-tritium (D-T) plasma operation for pulse lengths of at least $10 \mathrm{~s}$. The vacuum vessel provides the vacuum environment for the plasma as well as the first confinement barrier for radioactive materials. The vessel also serves as the support structure for all in-vessel components, provides the first level of nuclear shielding, and helps provide for the passive stabilization of the plasma. The vessel system includes the torus, the ports and port extensions, the gravity supports, the supports for internal components, the passive plasma stabilizing conductor, the internal control coils, and the integrated coolant/bakeout lines (Fig. 1).

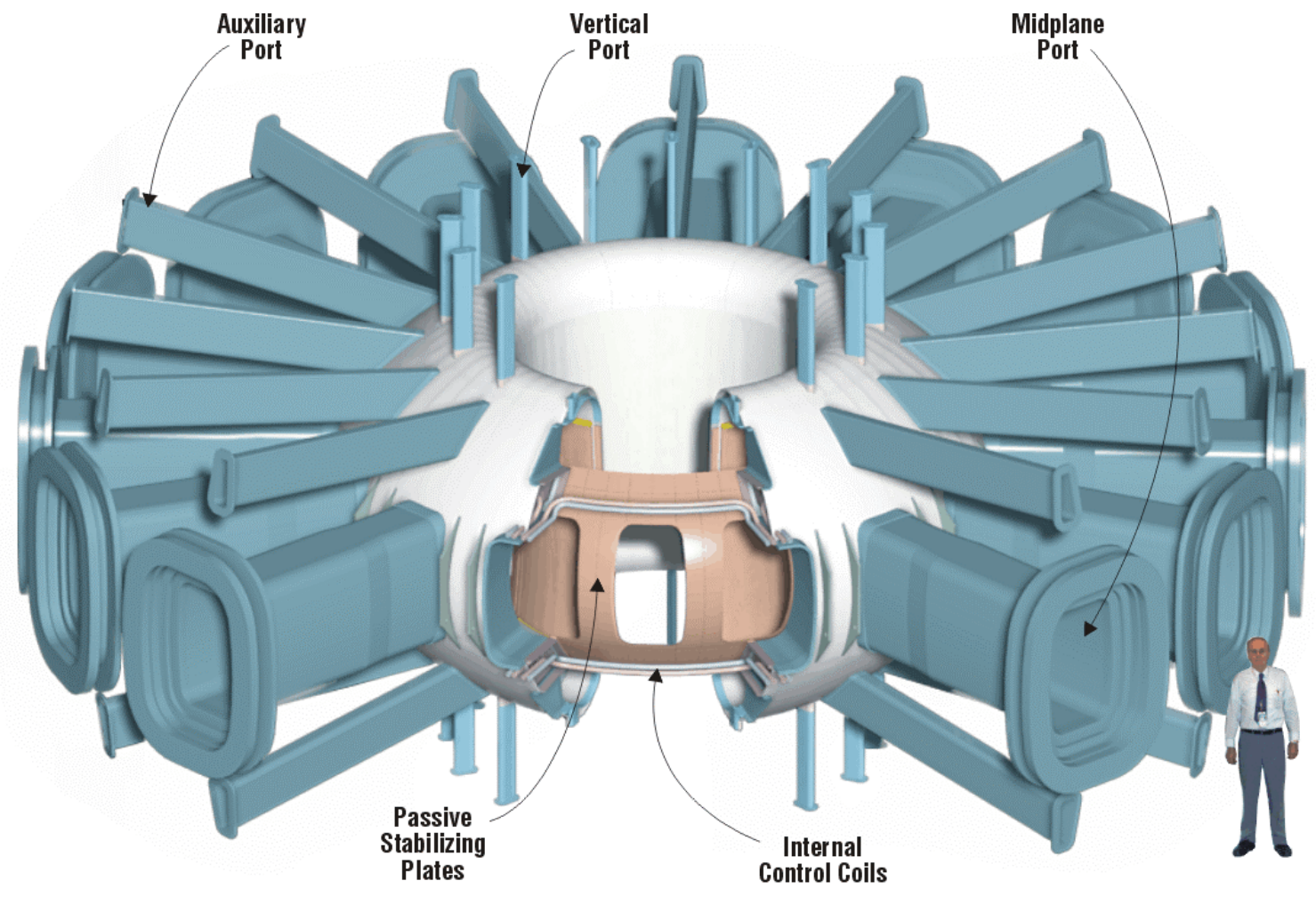

Fig. 1. Cutaway view of vacuum vessel with port extensions. 


\section{VESSEL CONCEPT}

The vessel torus is a double-wall sandwich structure consisting of 15-mm-thick inner and outer facesheets attached to poloidal ribs. The space between the facesheets, which varies from $20 \mathrm{~mm}$ on the inboard side to $540 \mathrm{~mm}$ on the outboard side, is filled with radiation shielding material and coolant. Water at $20-50^{\circ} \mathrm{C}$ and $1 \mathrm{MPa}$ is used to remove nuclear heating during normal operation. The water temperature is raised to $150^{\circ} \mathrm{C}$ for heating the vessel and internals during bakeout. The shielding material can be single-sized stainless steel balls with a packing fraction of about $60 \%$ or stacked plates with a similar packing fraction. The vessel parameters are summarized in Table 1 .

Table 1. Vacuum vessel parameters

\begin{tabular}{ll}
\hline Dimensions and weights & \\
Volume of torus interior & $35 \mathrm{~m}^{3}$ \\
Surface area of torus interior & $89 \mathrm{~m}^{2}$ \\
Facesheet thickness & $15 \mathrm{~mm}$ \\
Rib thickness & 15 to $30 \mathrm{~mm}$ \\
Weight of structure, including ports & 50 tonnes \\
Weight of torus shielding, incl. water & 80 tonnes \\
Power & $\sim 200 \mathrm{MW}$ \\
Direct neutron heating & $<40 \mathrm{MW}$ \\
Indirect load from first wall heat flux & \\
Cooling & Water \\
Coolant & $\sim 1 \mathrm{MPa}$ \\
Pressure & $<100^{\circ} \mathrm{C}, \sim 150^{\circ} \mathrm{C}$ \\
Normal operating temperature, & \\
$\quad$ bakeout temperature & \\
Materials & $316 \mathrm{~L} \mathrm{SS}$ \\
Torus, ports, and structure & $304 \mathrm{~L} \mathrm{SS}$ (tentative) \\
Shielding &
\end{tabular}

The primary advantages of the double-wall structure include higher bending stiffness (for a given total material thickness) and better integration of cooling and shielding. Most vacuum vessel designs in use [Joint European Torus (JET), JT60, DIII-D] and most designs on the drawing board [International Thermonuclear Experimental Reactor (ITER) and KSTAR] use full or partial double-wall vacuum vessels. Figure 2 shows an elevation section of the vessel and selected dimensions.

There are 16 sets of access ports around the torus, which are used for radio frequency (RF) heating, remote maintenance, diagnostics, and internal cooling. There are large 1.3 - by $0.7-\mathrm{m}$ midplane ports, upper and lower trapezoidal ports $\sim 0.1$ by $0.5 \mathrm{~m}$, and upper and lower vertical ports $\sim 0.05 \times 0.1 \mathrm{~m}$. The sets of port openings are identical at each of the 16 toroidal locations to provide structural and design symmetry. The port extensions may be varied to match their specific purpose. The port extensions are needed to extend the vacuum boundary past the toroidal field (TF) coil legs and through the thermal shield region.

\section{VESSEL LOADING AND ANALYSIS}

The vessel is designed to withstand large gravity, seismic, and electromagnetic (EM) loads, as summarized in Table 2. The total vertical load is estimated to be about $42 \mathrm{MN}$, while the net lateral load is about $14 \mathrm{MN}$. To react these loads, the vessel is supported near the midplane on the outboard side via vertical and lateral links to the TF coil structure. The vertical links are attached to the radial ribs

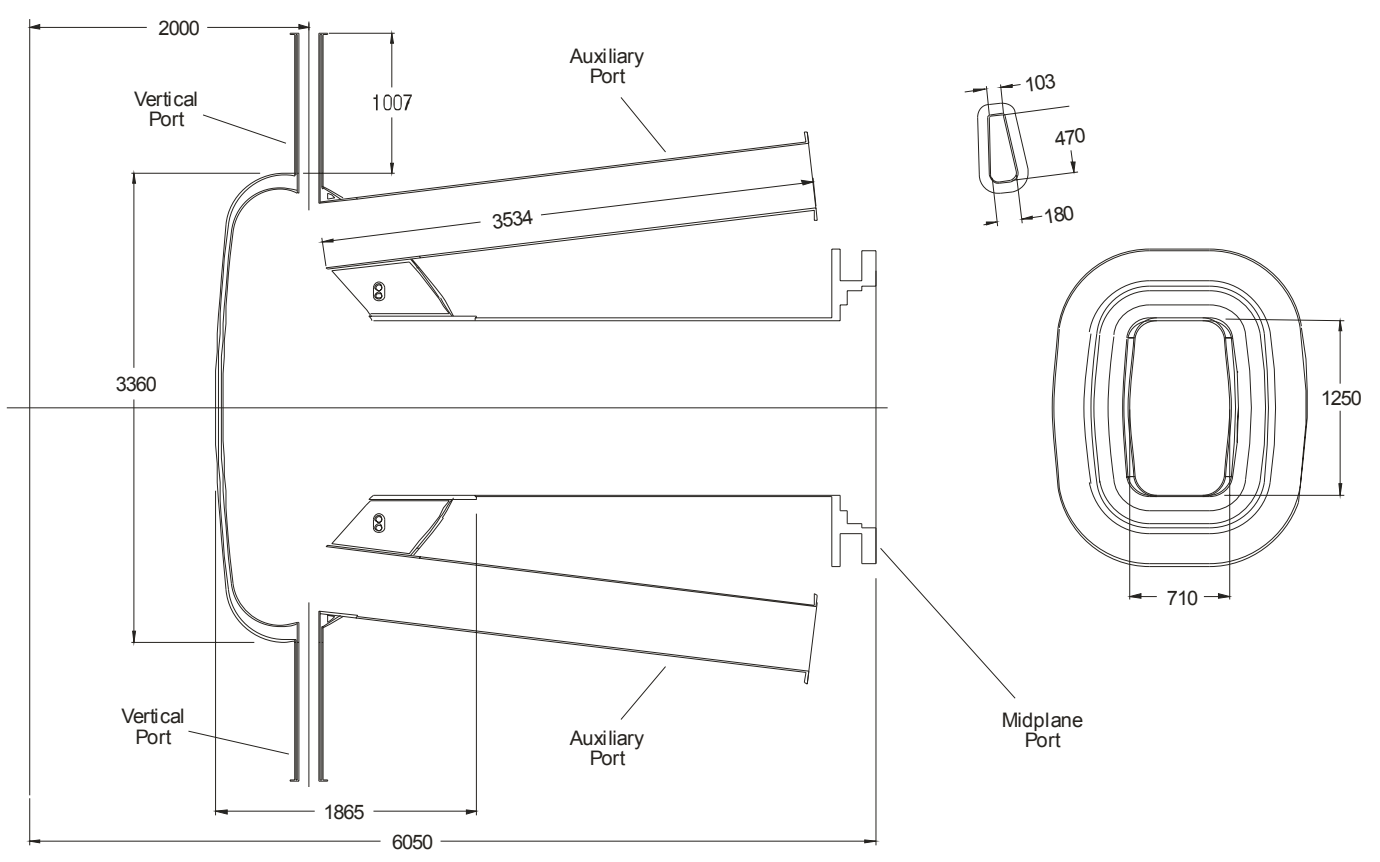

Fig. 2. Vessel and port dimensions. 
Table 2. Vacuum vessel loading conditions

\begin{tabular}{ll}
\hline \multicolumn{1}{c}{ Load } & \multicolumn{1}{c}{ Value } \\
\hline Gravity load & $\sim 3.5 \mathrm{MN}$ \\
Vertical displacement event & \\
(VDE) load & \\
$\quad$ Vertical & $16-32 \mathrm{MN}$ \\
$\quad$ Lateral, net & $6-11 \mathrm{MN}$ \\
Seismic load (assumed) & \\
$\quad$ Vertical acceleration & $0.2 \mathrm{~g}$ \\
$\quad$ Lateral acceleration & $0.2 \mathrm{~g}$ \\
Maximum total vertical load & $\sim 42 \mathrm{MN}$ \\
Maximum total lateral load & $\sim 14 \mathrm{MN}$ \\
Maximum local EM load & \\
$\quad$ Local pressure on vacuum & $\sim 4 \mathrm{MPa}$ \\
$\quad$ vessel from internal & \\
$\quad$ components & \\
EM load from TF ramp & $\sim 0.8 \mathrm{MPa}$ \\
Coolant pressure & \\
$\quad$ Normal operation & $<10 \mathrm{~atm}$ \\
Bakeout & $<10 \mathrm{~atm}$ \\
\hline
\end{tabular}

to spread the applied loads vertically into the vessel. This minimizes the local bending stresses in the vessel and provides a means for adjusting the vessel location globally relative to the TF coils. Lateral links are located near the vertical links and are tied to the top (and/or bottom) of the midplane ports.

The vessel must support all internal components, including the divertor assemblies, the passive stability structure, the poloidal limiters, and the first wall tiles. The outboard divertor modules are actively cooled via pipes at each of the upper and lower auxiliary ports. The two poloidal limiters are also actively cooled via piping located in the midplane ports. The first wall and inboard divertor are cooled by conduction to the copper passive stability cladding, which in turn is cooled by internal cooling passages connected to the vacuum vessel. All components must have robust supports to react the EM loads from a plasma disruption.

Preliminary structural analysis of the vessel indicates that the present dimensions are about right to support the various loads. A global finite-element model of the vessel geometry was constructed to calculate the stresses and deflections summarized in Table 3. As shown in the table, there are some peak stresses around the divertor supports at the top and bottom of the vessel that must be mitigated with additional structure. Stress-reducing reinforcements will be incorporated in the vessel design as part of the divertor support concept development.

\section{PASSIVE PLATES AND INTERNAL COILS}

As discussed in the physics section of Ref. 1, a set of highly conductive passive stabilizing plates and a set of active internal control coils must be integrated into the vacuum vessel. The geometry of the passive plate system is shown in Fig. 1. The passive plates consist of 25 to 30-mm-thick copper sheets bonded directly to the plasmafacing surface of the vacuum vessel. The sheets are actively cooled via internal water passages connected through manifolds to the vessel cooling system. A bonded connection is considered to be the most straightforward approach, since cooling can be provided directly by the copper plates to both the first wall tiles and the vessel, and continuous structural support can be provided to the passive plates by the vessel. The method of bonding has not been decided, but hot isostatic pressing (hipping) is a possibility.

Table 3. Preliminary Von Mises stress estimates for vacuum vessel

\begin{tabular}{|c|c|c|c|c|}
\hline \multirow[b]{2}{*}{ Load condition } & \multicolumn{2}{|c|}{ Torus and support points } & \multicolumn{2}{|c|}{ Ports and (Support points) } \\
\hline & $\begin{array}{c}\text { General stress }^{a} \\
\text { (allowable stress }= \\
195 \mathrm{MPa})\end{array}$ & $\begin{array}{l}\text { Peak local stress } \\
\text { (allowable stress }= \\
390 \mathrm{MPa})\end{array}$ & $\begin{array}{c}\text { General stress } \\
\text { (allowable stress }= \\
195 \mathrm{MPa})\end{array}$ & $\begin{array}{c}\text { Peak local stress }^{a} \\
\text { (allowable stress }= \\
260 \mathrm{MPa})\end{array}$ \\
\hline Vacuum load & $\sim 10$ & $\sim 25$ & TBD & TBD \\
\hline Coolant pressure $^{b}(1 \mathrm{MPa})$ & $<100$ & $\sim 230$ & TBD & TBD \\
\hline Simulated $\mathrm{VDE}^{c}$ & $<100$ & $\sim 240$ & $(\sim 300)$ & $(\sim 400)$ \\
\hline Halo Loads on divertor & 120 & 170 & $(\sim 150)$ & $(>400)$ \\
\hline Thermal stress from nuclear heating $d$ & 170 & 300 & $<200$ & $\sim 330$ \\
\hline TF ramp-up ${ }^{e}$ & $\sim 25$ & $\sim 32$ & TBD & TBD \\
\hline
\end{tabular}

\footnotetext{
$a_{\text {Estimated demarcation between general and peak local stress, peak primary }}+$ secondary $=3 \times \mathrm{S}_{\mathrm{m}}$.

$b_{\text {Stress values estimated from previous analysis. }}$

${ }^{c}$ VDE loads applied in simplified manner as body force, supports on outside.

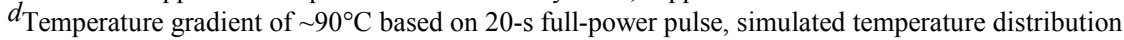

${ }^{e}$ Stress estimate based on $20 \mathrm{~s}$ current ramps in TF coils.
} 
A pair of control coils is also shown in Fig. 1. They are located between the outboard walls of the vessel above and below the midplane ports. Multiple turns of conductors are run in a permanent conduit that is routed directly through the outboard wall. The conductor will receive a moderately high radiation dose $\left(>10^{9} \mathrm{rad}\right)$ and will be insulated with either $\mathrm{MgO}$ or a polyimide insulation system. Redundant turns are being considered to mitigate one of the failure modes.

\section{FABRICATION AND ASSEMBLY}

The vessel is fabricated in octants, as shown in Fig. 3. Each octant consists of the torus, associated gravity and internal supports, short reinforcing stubs around the major port openings, and the active and passive stabilizer systems. The octant is assembled from 4 subassemblies, including upper, lower, inboard, and outboard subassemblies. These subassemblies contain the plasma facing skin and reinforcing ribs. The inboard and outboard subassemblies also have the copper stabilizer already bonded to the plasma-facing surface. The four subassemblies are welded together at the plasma skin and at each rib. The shielding is added between the ribs, and then the outer skin is added as strips between the ribs. This method insures leak tight, inspectable welds at each location.

At assembly, each vessel octant is rotated into the bore of a TF coil pair and connected via the support links. The $\mathrm{TF} / \mathrm{VV}$ subassemblies are then positioned relative to each other, with the mating joints located at radial planes between TF coils, through the center of the ports. Once all the octants are in place and positioned, they are welded together from the plasma side of the torus. The field joint for the double-wall structure uses splice plates on the plasma side to provide a means for accessing the coil-side facesheet from the plasma side of the torus. This type of joint has undergone significant, full-scale testing using remote welding equipment as part of the ITER research and development program ${ }^{2}$. After the vessel is welded, the gaps in the passive stabilizers are filled with plasmasprayed copper to complete the upper and lower stabilizing circuits. After the torus is welded, the port extensions are fitted and welded to the port stubs. This completes the vessel assembly.

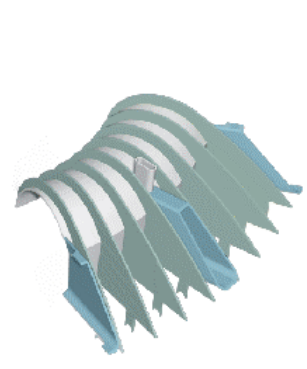

Weld ribs to inner skin, add ports

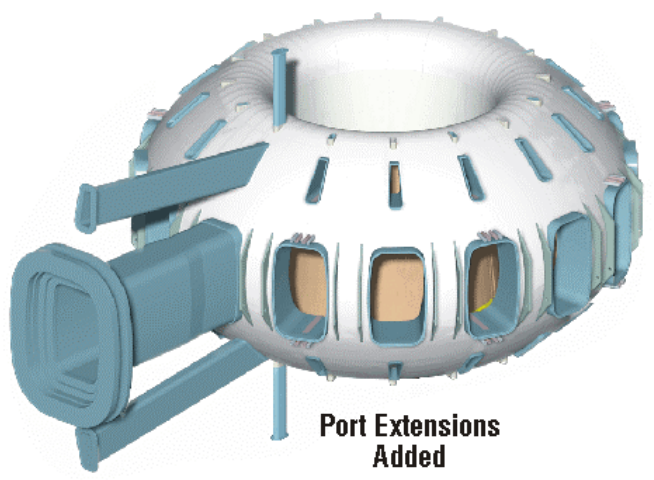

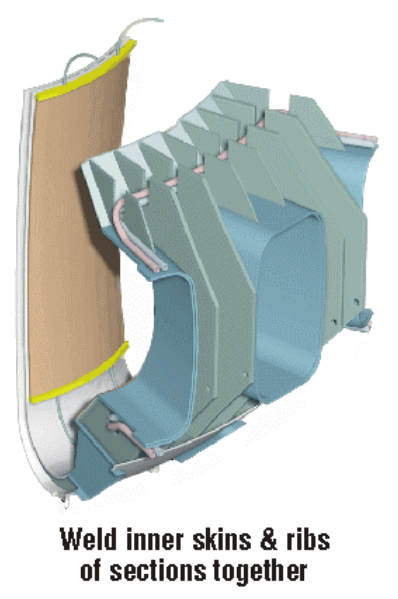
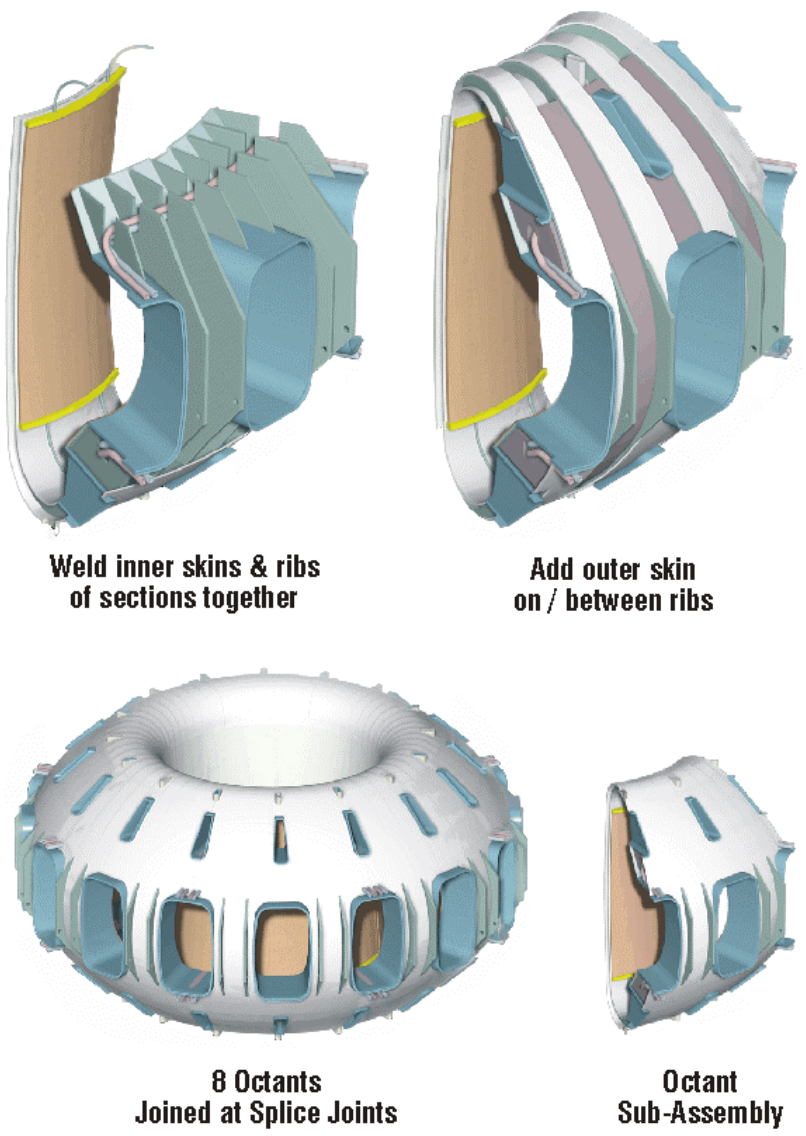

Fig. 3. Vacuum vessel assembly steps. 


\section{CONCLUSION}

The FIRE vacuum vessel serves multiple functions, including vacuum environment, safety barrier, nuclear shielding, and structural support for plasma facing components (PFCs) and passive stabilization of the plasma. A double-wall configuration was chosen to provide the best mix of cooling and shielding and to simplify fabrication. The passive stabilizing plates and active control coils are integrated into the vessel structure, and large ports are provided for heating, diagnostic, and maintenance access. The preliminary structural analysis indicates that this concept is feasible, but requires more reinforcement around ports and divertor supports. Additional analysis will be required during the conceptual design phase. The shielding, access port system, passive stabilizing system and active coil system are all adequate to meet design objectives.

\section{ACKNOWLEDGEMENTS}

Research sponsored by the Office of Fusion Energy Sciences, U.S. Department of Energy under contract DE-AC05-00OR22725 with UT-Battelle, LLC.

\section{REFERENCES}

1. FIRE Design Team; "Fusion Ignition Research Experiment (FIRE) Engineering Status Report for Fiscal Year 2000"; Princeton Plasma Physics Laboratory Report No. 8101030_FIREFYRPT FT.doc.

2. J. E. Maslakowski, ITER Remote Welding and Cutting Vacuum Vessel Demonstration, ITER/US/98/INV-VV-21, Boeing North American, September 1999. 